\title{
Lessons Learned from a Culturally Responsive Case Study
}

\author{
Kathryn K. Yamamoto \\ University of Hawai'i at Mānoa \\ 1337 Lower Campus Road; PE/A231 \\ Honolulu, Hawaii, United States 96822 \\ Tel: 1-808-95604386_E-mail: kky@hawaii.edu
}

\author{
Rhonda S. Black \\ University of Hawai'i at Mānoa \\ 1776 University Avenue; Wist 127 \\ Honolulu, Hawaii, United States 96822
}

Tel: 1-808-956-2367_E-mail: rblack@hawaii.edu

\author{
JoAnn W. L. Yuen \\ University of Hawai'i at Mānoa \\ 1410 Lower Campus Road; Bldg. 171F \\ Honolulu, Hawaii, United States 96822
}

Tel: 1-808-956-5462 E-mail: joyuen@hawaii.edu

Received: August 16, 2017 Accepted: September 18, 2017 Published: September 25, 2017

doi:10.5296/ijld.v7i3.11716 URL: https://doi.org/10.5296/ijld.v7i3.11716

\begin{abstract}
This article describes how researchers used a culturally responsive case study approach to understand how Native Hawaiian students made postsecondary decisions and the lessons they
\end{abstract}




\section{Macrothink}

International Journal of Learning and Development

ISSN 2164-4063 2017, Vol. 7, No. 3

learned through this process. Unique to this study were the steps taken in gaining entry to the research site and building relationships with the gatekeepers and student participants through culturally appropriate communication styles and activities. Concerted efforts were employed prior to and during the interviews to promote culturally responsive interactions (e.g., sharing of food). Implications are discussed for individuals teaching, counseling, and researching Native Hawaiian students and their families and include strategies for building relationships to gain entry and to gain confidence of participants; investigating social context prior to entry, discussion of rituals and routines, values and priorities; and viewing participant responses with respect to their worldview.

Keywords: Hawaiian, students, culture, relationships, transition 


\section{Introduction}

Most students arrive at their assumptions, beliefs, and values about education from their experiences in their home and community. Students who come from minority cultures often have different ways of understanding the world that at times creates conflict between their expectations of the educational system with their home culture and values (Schonleber, 2006). To address cultural gaps between home and school, Hawaiian scholars have called for increased cultural relevance in education and educational research (Kana'iaupuni, Ledward, \& Jensen, 2010). In a survey conducted by Kamehameha Schools, more than eighty percent of Native Hawaiian parents desired that their children pursue a postsecondary education: $62 \%$ envisioned that their children would continue their education at a four-year institution and $24.4 \%$ expected their children to enroll at a two-year college or technical school. Most of the survey respondents believed that education was positively correlated with success (Kamehameha Schools, 2009). However, in the State of Hawaii, native Hawaiian young adults had the lowest college enrollment rates among the state's major ethnic groups (Kamehameha Schools, 2014). For educators, administrators, guidance and vocational counselors to best serve Native Hawaiians, it is important to examine the lived experiences of native Hawaiian youth as they transition from secondary school to adult life.

\subsection{Background on Native Hawaiian Education}

To understand Hawaiian youth, one must adequately understand the history of Native Hawaiians and trace their struggle as a colonized people. Native Hawaiians were subjected to social, political, economic, and cultural turmoil due to Western colonization including dethronement and imprisonment of the reigning Hawaiian monarch, annexation of Hawai' $i$, and the ceding and procurement of indigenous lands (Mokuau \& Matsuoka, 1995; Silva, 1999). Until the arrival of Christian missionaries in 1820, Hawaiian was an unwritten language; thus, traditions, knowledge, and cultural practices were transmitted orally (Rayson \& Bauer, 1997).

The "Americanization" of the Kānaka Maoli (Hawaiian people) not only ended their political independence but resulted in the banning of their language in 1896 (Ho'omanawanui, 2004; Trask, 1993). The incongruence between the Native Hawaiian culture and western-based educational institutions has been noted by numerous researchers (Kana'iaupuni et al., 2010; Kawakami, 1999; Tharp, Estrada, Dalton, \& Yamauchi, 2000; Yamauchi, 2003) who have identified conflicts between students from cultures with more collectivist orientations and the individualist values held by Western educational institutions (Ballinger \& Noonan, 2004; Ogata, Sheehey, \& Noonan, 2006; Ogbu, 1990; Yamauchi, 2003). Differences between collectivist and individualist cultures appear in matters such as: (a) cooperation versus competition; (b) individual versus group orientation; (c) family responsibilities, gender and age roles; and (d) interaction styles (Triandis, 2001). These differences often create challenges for students from collectivist cultures who must learn to understand, adjust, and perhaps even forgo their own culture as they maneuver their way throughout the individualist culture of the traditional U.S. educational institutions. For many Native Hawaiians, school is seen as a place of conflict and struggle, a place where one must negotiate content, context, 
values, instructional strategies, and measures of accountability (Benham, 2006). Implications of past colonization continue in the participation and persistence of Native Hawaiian students in today's classrooms: in order to succeed in modern Hawai 'i, Native Hawaiian students have had to accept the values and behaviors related to success in Western culture. Native Hawaiians have had to put aside cooperative and collaborative values of laulima (joint action), kōkua (support), and ha'aha'a (humility) and are often faced with the dilemma of adopting values that promote individual achievement and competition (Kawakami, 1999). As an example, Native Hawaiian students may not feel comfortable speaking up in large or whole-group settings but may speak freely and learn more readily in smaller groups (Tharp et al., 2000).

Marginalization and socioeconomic challenges have also impacted the children leaving some disengaged and mistrustful of social institutions such as school (Kamehameha Schools, 2009). Differences in values, beliefs, and practices of the Hawaiian culture and the western school system have frequently resulted in reciprocal misinterpretation and dissention (Leake \& Black, 2005). Ramifications of this type of deficit model by a colonial educational system that professes that anything native was not good enough (Ho'omanawanui, 2004) has had profound and debilitating effects on Hawaii's children. Western models of education overlook indigenous philosophies and practices, relegate Native Hawaiians to low status, view them as part of the "problem" in need of fixing, and perpetuate this relationship with Western assumptions of success (Kawakami, 2003). Many remedial projects have been developed yet, have not addressed the deeper issues of alienation, under-representation, and conflicting epistemologies (Meyer, 2003). The shift from a Hawaiian-medium education to a western English-medium education has eliminated opportunities for personal connections between Native Hawaiians and their culture, and has confirmed the importance of Hawaiian language in maintaining the culture and traditional values. These connections are critical to holding families and communities together (Wilson \& Kamanā, 2006). To reconnect Native Hawaiians to their culture and linguistic identity, the first and probably most important standard for Native Hawaiian education is to incorporate cultural traditions, language, history, philosophy, and values (Kawakami, 2004, Kaomea, 2005; Meyer, 2003, 2005) in "meaningful holistic processes to nourish the emotional, physical, mental/intellectual, social and spiritual well-being of the learning community that promote healthy mauli (spirit) and mana (power/life force)" (Kawai'ae‘a, 2002, p. 17).

Educational research can be both an individual and collective experience when a strengths-based approach is used which integrates culture into the process thus benefitting those involved in the study by giving them a voice, insight, and power (Kana'iaupuni, 2005; Kana'iaupuni et al., 2010). Giving voice empowers people who might otherwise remain silent or who might be silenced by others. Voice gives the right and capacity to make oneself heard and to have one's experiences and viewpoints available to others (Ashby, 2011). Research may be conducted that builds family and community capacity by enhancing skills, expanding roles and responsibilities, and by giving voice to members. Involving participants in research enriches the lives of those studied, their communities and the field of study (Yuen, Dowrick, $\&$ Alaimaleata, 2006). In developing an understanding of an individual from the Native 
Hawaiian community, one needs to develop trust and an understanding of his/her historical and cultural values and beliefs. As participants and stakeholders in this study, it was important to understand that Native Hawaiians may be more socio-centric in nature and thus, place more emphasis on the self as an extension of the group. In the Native Hawaiian culture, the individual is validated by how they function in relationship to the collective society (Kenui, 2003). Therefore, when developing relationships with Native Hawaiian individuals it is important to incorporate relationships with their communities (i.e., leaders, families).

\subsection{Culturally Responsive Research}

We base our definition of "cultural responsiveness" on critical race theory (CRT). Critical race theory stresses listening to the experiences and counter-narratives of people from marginalized groups. However, for educators and scholars, it is still unclear how CRT could and should be applied in practical settings (Rogers \& Jaime, 2010). Our study draws from theorists who argue that "scholars must purposefully question the dominant culture process of conducting research with an eye toward its potential to reinforce injustice" (Rogers \& Jaime, 2010, p. 189). According to CRT, much of the research literature devalues the experience of minorities, individuals, and cultural or ideological outliers. Deemphasizing the experiences of outliers perpetuates a continued silence regarding social justice transformation in schools. In response, critical race theorists focus on the experiences of the outliers particularly as they directly contest the dominant culture's ideology (Ladson-Billings \& Tate, 1995). Relationship building is important to conducting culturally appropriate research. Culturally responsive researchers work build relationships based on caring behaviors, honesty and respect. These relationships give them a place within the community and an opportunity to serve as a resource (Vogler, Altmann, \& Zoucha, 2010; Wlodkowski \& Ginsbert, 1995). Culturally responsive researchers remain person-centered within the context of the whole life of the individual. This approach can be accomplished by maintaining a contextual understanding of the needs and strengths of participants and key stakeholders. The culturally responsive researcher does not assert a personal agenda and priorities, but rather, the researcher shares a genuine curiosity and willingness to learn about culture and diversity (Kenui, 2003).

\subsection{Framework}

Sociocultural approaches (Vygotsky, 1978) are based on the premise that human behavior takes place in cultural contexts mediated by language and other symbol systems. Sociocultural approaches underscore the interdependence of the individual and society in the construction of knowledge (John-Steiner \& Mahn, 1996). Ways of knowing (i.e., "learning") come about when the individual interacts with his/her environment and occurs with the assistance of a more knowledgeable other (Vygotsky, 1978).

Thus, the social nature of Native Hawaiians influenced the way we approached the study.The interplay and interdependence among the participants and (a) 'ohana (family and significant others, (b) äina (land), and (c) cultural elements such as hula and 'ólelo Hawai'i echoed in their narratives. Their mannerisms, speech, and decisions were reflective of Native Hawaiian culture and were highly influenced by the group ('ohana - the family). A sociocultural framework shaped the types of questions asked, informed how data were analyzed, and 
provided a call to action (Creswell, 2014). In this study, we attempted to recognize relational and historical context in giving voice to Native Hawaiian students. This article details how we used a culturally responsive case study approach to promote participation and engagement of Native Hawaiian students as they told us about their post-secondary decision-making processes. We acknowledge our diversity, positionality, and attempt to address possible bias throughout our research. The first author is a fourth generation, Japanese-American and who was born and raised in Hawaii; the second author is a Caucasian-American who was born in the continental United States and has lived in Hawaii for over 20 years; and the third author is part Native Hawaiian who was born and raised in Hawaii. Unique to this process were the steps taken in gaining entry to the research site and building relationships with the gatekeepers and student participants through culturally appropriate communication styles and activities.

\section{Method}

We used a multiple case study approach that was bounded by the physical parameters of the chosen site (Department of Education Hawaiian charter school), by participant demographics (Native Hawaiian high school student with a learning disability), and by time (academic school year) (Creswell, 2007; Jones, Torres \& Arminio, 2006). The case study method provided a means for participants to tell their story from a personal perspective (McLeod, 2013). We modeled the method after Meyer's study (2003) in which she approached her participants (mentors) not as a researcher in need of hard data but rather as a "student" in need of assistance. We collected data through: (a) individual semi-structured interviews with five student participants (four males and one female), (b) observations, (c) interviews with the school's Student Services Coordinator, and (d) artifacts (e.g., IEPs, workshop assignments).

\subsection{The Research Site Na Keiki o Ka'Āina}

(NKKA) a pseudonym, is a charter school located on the island of $\mathrm{O}^{\prime}$ ahu in the State of Hawai' $i$. The school's curriculum integrates core subjects into place-based and project-based learning. We chose this site because it was a Hawaiian culture-based charter school with $97 \%$ of the school population identified as Hawaiian (Note: reference to website not shown in order to protect confidentiality of participants).

\subsection{Gaining Access}

One of the tasks of undertaking fieldwork involved gaining access to the Hawaiian-focused charter school and ensuring that that those associated with it would serve as participants for the study. One method we used for gaining access was using endorsements from "authorities" (Shenton \& Hayter, 2004). The first author met with a respected "elder" in the Native Hawaiian community to share the intent and purpose of the proposed study. With his blessing, the elder introduced the first author to one of the school founders. This was not an engineered process but one that occurred organically because of past established relationships.

Prior to initiating this study, one of the school's founders provided the following valuable advice: 
I think the bigger thing is establishing a sense of trust...knowing who you are... where you come from.... why you're there. We had different folks who were doing graduate level research.... writing their dissertations doing things here...the students seem to respond best to the people they've seen around... whether they know, "oh this is aunty"... whether or not she's Hawaiian, or whatever...she's been around. They see the other teachers, you know talking and showing respect for this person...then they are more likely to open up (Note: name withheld to protect confidentiality of study participants).

We worked toward laying the groundwork for gaining access to the school and to prospective participants for this study. Although the first author was born and raised in Hawai' $i$, she was not a "true" insider, she recognized that it was important to respectfully navigate through this tender territory and not appear overly familiar or pandering with students, parents, and school staff. The first author met with various school staff (principal, vice principal, counselor, administrative assistant, and various teachers) and shared with each of them plans for the study and a copy of the study's abstract. She openly and honestly answered questions and concerns posed. We promoted "reciprocity" by informing the school administration and staff that we would share findings with them. This concept of "reciprocity" indicated that entry is best ensured when the investigator agrees to share his/her findings with the organization and that participation in the study can be shown to benefit the organization (Shenton \& Hayter, 2004).

\subsection{Selection of Participants}

We used a purposeful, criterion-based sampling (Creswell, 2014) to ensure that the data collected would be rich and detailed and that the participants selected could best inform the research questions (Sargeant, 2012). We relied on insiders (i.e., administrators, teachers, and staff) to identify individuals who met the study criteria, were willing to participate in interviews, and had their parents' permission to participate. The first author then met with parents and students to ensure appropriateness of participation for this study.

The selected participants were based on the following criteria: (a) self-identified as Hawaiian or part-Hawaiian; (b) identified by the Department of Education as having a learning disability; (c) a prospective first-generation college student; and (d) enrolled in $9^{\text {th }}-12^{\text {th }}$ grade at NKKA. As in other qualitative research, the sample size for this study was not predetermined but dependent on the number required to fully inform on the phenomenon being studied (Sargeant, 2012).

One of the initial challenges of this study was determining how we would define "Native Hawaiian." In our research, we discovered that "how" an organization or institution defined "Native Hawaiian" varied greatly. For example, the State of Hawai'i Data Book 2014 (Department of Business Economic Development \& Tourism, 2014) and the U.S. Census Bureau (Hixson, Hepler, \& Kim, 2012) both relied on individuals self-identifying as Native Hawaiian. In contrast, the Kamehameha Schools Bishop Estate defined Native Hawaiians as those who can substantiate Hawaiian ancestry through birth certificates of parents and grandparents (Kamehameha Schools, 2009) and the Hawaiian Homes Commission Act of 1921 defined Native Hawaiians as "descendants of not less than one-half part of the blood of 
the races inhabiting the Hawaiian Islands previous to 1778" (Hawaiian Homes Commission Act, 1921). For the purpose of this study, we relied on the participants to self-identify as Native Hawaiian.

\subsection{Culturally Responsive Data Collection Methods}

\subsubsection{Mini Workshops}

To build rapport and gain trust, the first author established a presence within the school and with the students and their families. The workshops provided an informal, culturally responsive venue to develop rapport with study participants and offered opportunities for them to build trust with the primary researcher. Two main sessions were conducted: one for a large group of approximately $309^{\text {th }}$ and $10^{\text {th }}$ graders and a second workshop for $11^{\text {th }}$ and $12^{\text {th }}$ graders. In line with cultural responsiveness of working with Native Hawaiian learners, the workshops were designed to be interactive with students working alongside their peers, with open communication, and sharing of tools and supplies (Tharp et al., 2000). The purpose of the first workshop entitled: "Create Your Own Success Story," was to provide an opportunity for the students to begin to think about their dreams and hopes for the future. This activity allowed students to create collages and drawings on poster boards that reflected their dreams for their futures (adapted from Lancaster \& Johnson, 2004). A large variety of magazines, glue sticks, scissors, markers etc. were provided for students to create their storyboards. Participants were to describe or find pictures of activities and events in their personal, professional and community lives 10 years in the future.

The second workshop entitled, "How Can I Do Everything that I Need to Do?" (Loo, 2009), focused on helping students to identify priorities and learn time management concepts. Materials included one large empty glass jar, large rocks, pebbles, and sand. All three materials would only fit in the jar if placed in a particular order (i.e., large rocks, pebbles, and sand). The demonstration was followed with a discussion about what the items symbolized: large rocks were identified as the important activities in their lives; the pebbles represented less important activities, and the sand represented activities that waste the most time. Students reviewed their values and identified people and activities that represented the big rocks, pebbles, and sand in their lives.

\subsection{2 "Talking story" (Interviews)}

One-on-one interviews took place after school hours and were held on the school grounds at the request of school administration and parents. Meetings took place either in an unoccupied classroom or in the school administrator's meeting room. Although we did have the option to meet in an open-air setting, other students were still on campus and we chose to meet in more private quarters to maintain participant's confidentiality. An indoor setting was also preferable to ensure that the interviews were recorded as optimally as possible. In addition, if the interviews were held outdoors, we would be faced with extraneous noises (e.g., voices of students and faculty, sounds of motor vehicles, wild chickens, wind in the trees, etc.).

The semi-structured open-ended interview format allowed participants to speak freely and to describe their experiences in detail with minimal prompting. The "talk-story" discourse 
pattern (Tharp et al., 2000) was used to provide a more culturally compatible context for the interviews. Particularly true for cultures with a strong oral tradition, storytelling is a commonly used method of sharing knowledge or an understanding of self, a place and time, and may be a more comfortable form of communication (Umemoto, 2001). McDermott et al. (1980) concurred by suggesting that those interested in working with or helping individuals from the Native Hawaiian community adopt a low-key, sincere manner, to develop personal contact. The Hawaiian culture and history is captured by centuries of rich oral tradition, which underscores the importance of "talking story" (Teter, 2010). Talking story is valuable in its ability to provide contextual data on the perceptions, meanings and experiences of individuals, which enhances the researcher's ability to be culturally responsive (Affonso, Shibuya, \& Frueh, 2007). Oftentimes simply through "talking story," concerns and problems will come up through this undirected exchange. The use of Hawaiian "talk story" includes a high proportion of turn taking that involves a joint performance (Affonso et al., 2007; Au \& Mason, 1981; Rynkofs, 2008) and creates an interview of sharing stories rather than interrogation.

The interviewer's mode of communication during the talk story sessions (i.e., interviews) was carefully selected. Although the interviewer typically speaks in Standard English, she was born and raised in Hawai'i and grew up speaking the local dialect of Hawaiian Creole English (known by locals as "pidgin English"). As this was the primary language of student participants, during these sessions, the interviewer spoke in "pidgin English" to promote "talk story" and a more informal, relaxed, and free flowing conversation. A semi-structured interview guide ensured that all participants were asked the same questions; however, the precise wording of the questions for the interviews and their order was not predetermined. Questions about postsecondary goals included: What you'd like to do after you graduate? What things are in place or will be in place to help you to reach your goal(s)? Who/what will help you with those struggles? Questions about the impact of disability on their future goals included: How would you describe yourself as a student? Has anything gotten in the way of your learning process? If so, please describe. Questions about the influence of culture included: What does it mean to you to be Hawaiian? How does your Hawaiian culture influence your school experiences? How does your culture influence your life outside of school? Questions about being a first-generation college included: Has anyone in your family attended college/university? If so, tell about their experience, did they graduate? Has this person influenced you or talked to you about what you want to do after you graduate from high school?

Although the participants were familiar with the interview setting (their school), the interview process was still a contrived situation and foreign to how knowledge is usually exchanged among the Hawaiian people. The first author who served as the interviewer, made concerted attempts to promote a comfortable, culturally responsive, respectful, experience for the participants. The interviews took place on the grounds of $\mathrm{Na}$ Keiki o Ka 'Äina just after the close of the school day. This allowed the interviewer to sit with the participants (while they were in their natural environment), listen to their words, observe nuances in tone and body language, view artifacts, and record and report these in-depth findings. The interviewer began 
each session with the exchanging of pleasantries and offering food and drink. Sharing food is the way Hawaiians care for one another and this sharing builds a strong family and community. The sharing of food is at the center of establishing and maintaining social relationships (McMullin, 2005). This prelude to the actual interview also allowed the student time for physical refreshment, to acclimate, and relax before engaging.

\subsubsection{Circle of Dreams Activity (Mount, 1992)}

Another tool that was incorporated into the data collection process was the use of storyboards to assist the participant in describing their present and future situations. Offering the participants an optional mode for communication (i.e., pictorially followed by a discussion) to describe their hopes, dreams, and values was consistent with traditional Hawaiian methods of learning that took place "by doing" and through the process of "talking story." The participants were provided with a white poster board and a variety of colored markers. They were asked to write their names in the middle of the poster board and to draw a circle around it. They were then instructed to draw pictures or write descriptions of the people, activities, and things that were important in their lives at present. When the participant was finished with the first circle, we discussed what they drew or wrote in their "Circle of Dreams." Interview questions were included in the discussion. Participants then drew a second circle around the previous circle and filled that circle in with drawings and/or words of people, activities, things that they would be involved with at the time of their graduation from high school. The third circle was to include events, people, activities they would like to be involved with at age 21. Upon their completion of this final circle, questions were asked to gain a better understanding of their thought processes during their transition process. Incorporating the Circle of Dreams activity into the interview process added greatly to the data collection process. For example, initially, students were not very forthcoming in answering direct questions and responded with brief phrases. When asked to describe the people and things in their drawings, (e.g., close family members, things of value including love of the land), a more candid and detailed discussion took place. Outcomes of this activity included discussions on the value of relationships and the value of collective (vs. individualist) dreams.

Upon reviewing the transcripts from all the first interviews, there were still unanswered questions. The first author, met with each participant a second time to not only review their original interviews and ask if they felt they wanted to share further information (member checking) but also to probe further into specific areas of their transition process. Each interview was recorded with 2 digital recorders (second recorder as a backup) and transcribed on the day that the interview took place. Transcribing each recording on the day that the interview took place was also a good strategy as the discussion was still fresh facilitating the transcribing process and more importantly, comprehension of the topic at hand.

\subsection{Checking Biases}

In general, qualitative research focuses on understanding processes that are defined by relationships. To document this dynamic and this focus coupled with the fact that the qualitative researcher is the instrument of research (i.e., the instrument for collecting and 
analyzing data) requires the researcher to be calibrated to the culture. The human instrument comes with limitations and biases that may impact the study. For this reason, it is important that the researcher identify and monitor these subjectivities as they may influence their interaction with the participants and subsequently the collection and interpretation of data (Merriam, 2002). As we entered the study, we knew that we needed to identify, acknowledge, and continually revisit these biases and preconceptions throughout the study. We also needed to check for conscious and unconscious biases. The use of language or choice of words was important in not only the interviewer's interaction with study participants but also in interpreting the data and the write up of this study. By using co-authors for peer debriefing, the interviewer checked herself for biased assumptions or condescending language. The primary researcher met with colleagues to identify (a) overemphasized points; (b) underemphasized points; (c) vague descriptions; (d) biases or assumptions made by the researcher (Lincoln \& Guba, 1985). The colleagues/peers asked questions to help the first author understand how her personal perspectives and biases affect the findings (Spall, 1998). Twice per month, the first author met individually with the colleagues who each played a different role (i.e., knowledgeable about Hawaiian culture; qualitative methodology). The conversations were used to check and challenge assumptions, and get feedback regarding interpretation of the interview and observation data. The conversations ranged from discussions on accessing participants in culturally appropriate ways to grappling with thoughts and making connections. In addition, a peer reviewer was used to verify whether an "expert" agreed with the coding process (Houghton, Casey, Shaw, \& Murphy, 2013).

\subsubsection{Addressing Social Distance and Subjectivities}

There were also several factors that could contribute to social distance between the researchers and the participants: education, socioeconomic status, language. The first author, who conducted the interviews, was aware of the social distance between the study participants and herself due to gender (four of the five participants were boys), age, education, background, language, and ethnicity. Although she recognized that it would be impossible to completely bridge the gap of social distance, she made attempts to make the participants as comfortable as possible. Prior to the 1:1 interviews, the first author presented mini workshops described above. This allowed the participants to see her on campus on several occasions as she interacted with both students and faculty. The first author addressed subjectivities by taking notes along with taped interviews; writing journal entries of thoughts, feelings, and surprises. Member checks were conducted after transcribing and reviewing the first round of participant interviews (Creswell, 2014; Denzin \& Lincoln, 2000). The first author reviewed transcriptions with each participant to ensure their thoughts and feelings were accurately described.

\subsection{Triangulation of Data}

The first author observed the participants both formally and informally (i.e., during the mini workshops, at interview sessions, at Individualized Education Program (IEP) meetings, and informally on campus). Attendance at the IEP meetings allowed us to contextualize ideas that arose out of the interviews and served to ground our conversations. We collected documents 
on past and present school activities/reports, newsletters, IEPs, and storyboards created by students. The documents provided a way to support or refute other data collected. One of the most effective techniques for studying cultural belief systems is for the researcher to immerse themselves as deeply in the culture as possible and then to integrate and organize the amassed information into a rational series of propositions (Spradley, 1980). After collecting data from interviews, observations, participation at IEP meetings, and reviewing artifacts, we used categorical aggregation to analyze and interpret data. In this form of data analysis and interpretation, the researcher seeks a collection of instances from the data hoping that issue-relevant meanings will emerge (Creswell, 2014). The first author reviewed all the information to get a sense of the data as a whole. She then wrote down findings in the form of reflective notes and memos and began summarizing her field notes. It was important that a detailed description of the case (i.e., major players, site, and activities) was added to offer a foundation and background information for studying observations and interviews. As the first author was transcribing, she wrote methodological notes (vs. analytical notes). For example, she jotted down notes on how a particular question was asked, what should have been done differently, how to follow-up on information, and used lessons learned and insights gained for subsequent interviews. As previously mentioned, throughout the process, the first author arranged meetings with different colleagues for peer debriefing (Spall, 1998). These debriefing sessions also provided a 'safe' forum to test assumptions, explore emerging themes, authenticate researcher interpretations, and establish credibility (Denzin \& Lincoln, 2000). Next, the first author met with each participant and presented the student with a hard copy of their transcripts to review. She discussed both interviews as well as her interpretation of the interview transcripts (i.e., member checks). She wanted to ensure that: (a) the interviews were transcribed accurately, and (b) that she had interpreted their words correctly. We searched for larger domains (e.g., family) and attempted to organize members of each domain. We looked closely at the words the participants used and looked for similarities among dimensions of contrast (represent a more general concept than particular traits associated with a term) for all domains (Spradley, 1980).

\section{Discussion: Strengths and Barriers}

Lessons learned from this study included a reflection on the methods we utilized in conducting this culturally responsive case study. Our attempt to promote participation and engagement of Native Hawaiian students in their transition planning process presented both successes and challenges. In this section, we address some of the strengths and barriers to this case study.

\subsection{Strengths}

To uncover the participants' voices, a number of nuances to traditional qualitative methods were used. A careful look at our culturally responsive process noted that there were positive results in our approach to gain entry and gather data. For example, in the Hawaiian culture, an individual defines himself or herself by the quality of his or her relationship with family members and the community (Ewalt \& Mokuau, 1995). Our study supported this principle. For example, it was important to spend time to develop relationships at every stage of the 
study. It took close to one year to develop the relationship with "insiders" (i.e., elder, founder, principal, parents, transition teacher) at the charter school to gain entry. It then took another six months to develop relationships with students and teachers by providing mini-workshops to not only the identified participants but to all students (the collective unit) before gathering data.

To address insider-outsider issues, the primary researcher followed the advice of an insider and took the time to be seen on campus, to interact informally with staff, family members, and students, prior to any formal interaction. It was important to develop a means for the participants to feel free to talk about their plans within the context of other people and roles in their lives - role as a son, a brother, and a member of a hula halau. As indicated in the methods section, the Circle of Dreams Activity (Mount, 1992) was used so that students could talk about their own dreams within the context of "other people" (family members and close friends) which was more culturally appropriate than talking about themselves.

Another strength of our study was that through this process we continued to develop awareness of our participants' social identities and used this knowledge to cultivate relationships and better understand the individual student stories (Rodriguez, et al., 2011). The data we gathered from large group interactions and activities were used to develop relationships with individual students through the Circle of Dreams activities, which then led to 1:1 interview sessions where we discussed values found in Circle of Dreams activity in more detail. In addition, we utilized various strategies and activities (both communal and individual data collection methods) to "expand and enhance the participants' ability to co-construct knowledge within the research setting" (Rodriguez et al., 2011, p. 404). Here we used group work, the creation of story boards, and 1:1 interviews to provide participants with several opportunities to reflect on values and look toward their future.

\subsection{Barriers}

Knowing that researchers interpret their experiences and work as the result of many complex variables (Ford, 2010), it was important for the researchers of this study to acknowledge our own identities, experiences, histories (Ebersole, Kanahele-Mossman, \& Kawakami, 2016) and privilege and thus, the lens from which we view others (Ford, 2010). We recognized that we are "outsiders" and needed to be reflexive about our own stories and how our personal stories impacted the research experience (Rodriguez et al., 2011). Throughout the study, we needed to recognize, accept and revisit our lived experiences (even the lived experience of the native Hawaiian researcher) which are unlike those of the participants in this study.

Like Ashby (2011), as outsiders, we grappled with the issues of "giving voice" and asked ourselves, "Were we giving voice?;" "Was it ours to give?;" "Whose voice is it really?;" and "Who benefits from the telling?" Perhaps the most important lesson was that we needed to heed the warnings of researchers who have come before. Kaomea (2005) suggested that the most helpful role that could be assumed by non-natives in teaching indigenous or researching indigenous communities was to work collaboratively with them, to listen closely to their wisdom and concerns, and just as poet 'Imaikalani Kalahele (2002) so eloquently wrote to "stand behind" the people so that it is their voices that can be heard: 
If to help us is your wish then stand behind us.

Not to the side

And not to the front (Kalahele, 2002, p. 51).

\section{Limitations and Future Research}

We recognized several limitations in this research. First, the study took place in a very unique setting with five students. We do not claim that this is generalizable and the only way to conduct culturally appropriate research. The current study was just one effort that may or may not apply to the settings of other researchers. We do, however, believe that there is benefit from the methods used to gain entry and to discover and understand the culture of the students through their eyes. The findings of this study are significant to those who serve students from collectivist backgrounds (e.g., teachers, counselors, administrators, etc.). The conflict between the collectivist view held by the Native Hawaiian culture and the individualist view held by most school systems needs to be articulated and discussed in undergraduate and graduate education classes.

Educators, researchers, administrators, and service providers need to be aware of who they are and be cognizant of their values in interactions with Native Hawaiian students and their families. In the educational setting, we must teach in culturally relevant ways. Although the students in this study were Native Hawaiian, researchers who study other collectivist populations (e.g., Hispanic, Native American) may learn from methods we used. For example, the literature tells us that Native Hawaiians belong to a collectivist culture where individuals tend to forgo individual goals and focus on what they can do for the group, for the family. Native Hawaiian students from the interdependent collectivist culture highly value skills that are other-oriented vs. self-oriented. Being sensitive to this can influence how researchers approach gaining entry and how questions are asked. Framing questions in terms of how students' future goals related to family vs. thinking about what they wanted independent of the family needs and values.

\section{Conclusion}

The Native Hawaiians are a strong, proud, and resilient people. Although they have experienced many challenges throughout history, they continue to press on for the good of their community, holding on to their culture, language, dance, and customs. This article describes how researchers used a culturally responsive case study approach to understand how Native Hawaiian students made postsecondary decisions and the lessons learned throughout this process. Unique to this study were the steps taken in gaining entry to the research site and building relationships with the gatekeepers and student participants through culturally appropriate communication styles and activities. Concerted efforts were employed prior to and during the interviews to promote culturally responsive interactions (e.g., sharing of food). Implications were discussed for individuals teaching, counseling, and researching Native Hawaiian students and their families and included strategies for building relationships to gain entry and to gain confidence of participants; investigating social context prior to entry, discussion of rituals and routines, values and priorities; and viewing participant responses 
with respect to their worldview. Further research on Native Hawaiians is needed to better understand how to meet both home-culture and Western educational needs. This essential task "must not only meet rigorous scientific standards but also honor the wisdom of native/local traditional knowledge" (Benham, 2006, p. 7). It is now up to all those who work with Native Hawaiian students to be more culturally educated and responsive.

\section{References}

Affonso, D. D., Shibuya, J. Y., \& Frueh, B. (2007). Talk-Story: Perspectives of children, parents, and community leaders on community violence in rural Hawai'i. Public Health Nursing, 24(5), 400-408. https://doi.org/10.1111/j.1525-1446.2007.00650

Ashby, C. (2011). Whose "voice" is it anyway?: Giving voice and qualitative research involving individuals that type to communicate. Disability Studies Quarterly, 31(4). https://doi.org/10.18061/dsq.v31i4.1723

Au, K. H. P, \& Mason, J. M. (1981). Social organization factors in learning to read: The balance of rights hypothesis. Reading Research Quarterly, 17(1), 115-152. https://doi.org/10.2307/747251

Ballinger, R. A., \& Noonan, M. J. (2004). Transitioning students with disabilities in a rural native Hawaiian community: One teacher's perspective. Rural Special Education Quarterly, 23(4), 17-24. https://doi.org/10.1177/875687050402300404

Benham, M. (2006). A challenge to native Hawaiian and Pacific Islander scholars: What the research teaches us about our work. Race Ethnicity and Education, 9(1) 29-50. https://doi.org/10.1080/13613320500490705

Creswell, J. W. (2007). Qualitative inquiry and research design: Choosing among five traditions. Thousand Oaks, CA: Sage.

Creswell, J. W. (2014). Research design: Qualitative, quantitative, and mixed methods approaches (4th ed.). Thousand Oaks, CA: Sage.

Denzin, N. K. \& Y. S. Lincoln, Y. S. (2000). Handbook of qualitative research (2nd ed.). Thousand Oaks, CA: Sage Publications.

Department of Business, Economic Development \& Tourism (2014). 2014 State of Hawaii Data Book. Retrieved from http://dbedt.hawaii.gov/economic/databook/db2014/

Ebersole, M., Kanahele-Mossman, H., \& Kawakami, A. (2016). Culturally responsive teaching: Examining teachers' understandings and perspectives. Journal of Education and Training Studies, 4(2), 97-104. https://doi.org/10.11114/jets.v4i2.1136

Ewalt, P. L., \& Mokuau, N. (1995). Self-determination from a pacific perspective. Social Work, 40(2), 168-175. Retrieved from http://www.jstor.org/stable/23718033

Ford, D. Y. (2010). Conducting research that is culturally responsive. Gifted Child Today, 34(3), 25-27. https://doi.org/10.1177/107621751103400307 
Hawaiian Homes Commission Act. (1921). Retrieved from http://www.hawaii-nation.org/hhca.html.

Hixson, L., Hepler, B. B., \& Kim, M. O. (2012). The native Hawaiian and other pacific islander population: 2010. (U.S. Census Bureau, Report No. C2010B4-12). Retrieved from https://www.census.gov/library/publications/2012/dec/c2010br-12.html

Ho'omanawanui, K. (2004). Hā, mana, leo (Breath, spirit, voice) - Kānaka maoli empowerment through literature. American Indian Quarterly, $28(1 \& 2), 86-91$.

Houghton, C., Casey, D., Shaw, D., \& Murphy, K. (2013). Rigour in qualitative case-study research. Nurse Researcher, 20(4), 12-17. https://doi.org/10.1353/aiq.2005.0011

John-Steiner, V., \& Mahn, H. (1996). Sociocultural approaches to learning and development: A Vygotskian framework. Educational Psychologist, 31(3/4), 191-206.

Jones, S. R., Torres, V., \& Arminio, J. (2006). Negotiating the Complexities of Qualitative Research in Higher Education. New York: Routledge.

Kalahele, I. (2002). Poetry and Art by 'Imaikalani Kalahele. Honolulu: Kalamaku Press.

Kamehameha Schools (2009). Native Hawaiian educational assessment update 2009: A supplement to Ka Huaka'i 2005. Honolulu: Kamehameha Schools, Research \& Education Division.

Kamehameha Schools. (2014). Ka Huaka'i - Native Hawaiian Educational Assessment. Honolulu: Kamehameha Publishing.

Kana'iaupuni, S. M. (2005). Ka'akālai Kū Kanaka: A call for strengths-based approaches from a Native Hawaiian perspective. Educational Researcher, 34(5), 32-38. https://doi.org/10.3102/0013189X034005032

Kana'iaupuni, S., Ledward, B., \& Jensen, U. (2010). Culture-based education and its relationship to student outcomes. Honolulu: Kamehameha Schools, Research \& Evaluation.

Kaomea, J. (2005). Indigenous studies in the elementary curriculum: A cautionary Hawaiian example. Anthropology and Education Quarterly, 36(1), 24-42. https://doi.org/10.1525/aeq.2005.36.1.024

Kawai'ae'a, K. (Ed.). (2002). Nā honua mauli ola. Hawai'i guidelines for culturally health and responsive learning environments. Hilo, HI: Ka Haka Ula O Ke'elikōlani and Native Hawaiian Education Council.

Kawakami, A. J. (1999). Sense of place, community and identity: Bridging the gap between home and school for Hawaiian children. Education and Urban Society, 32(1), 18-40. https://doi.org/10.1177/0013124599032001002

Kawakami, A. J. (2003). Where I live, there are rainbows: Cultural identity and sense of place. Amerasia Journal, 29(2), 67-79. https://doi.org/10.17953/amer.29.2.j482878555087346 
Kawakami, A. J. (2004). Issues central to the inclusion of Hawaiian culture in $K-12$ education. Hūlili: Multidisciplinary Research on Hawaiian Well-Being, 1, 111-130.

Kenui, C. K. (2003). Na kanaka maoli: Indigenous people of Hawaii. In J.D. Robinson and L.C. James (Eds). Diversity in human interactions: The tapestry of America. Oxford University Press: England. https://doi.org/10.1093/acprof:oso/9780195143904.003.0006

Ladson-Billings, G., \& Tate, W. F. (1995). Toward a critical race theory of education. Teachers College Record, 97(1), 47-68. Retrieved from https://www.researchgate.net/profile/William_Tate/publication/279676094_Toward_a_Critica 1_Race_Theory_of_Education/links/569803e908aea2d74375dba0.pdf

Lancaster, P., \& Johnson, R. (2004). The road to success. Lawrence: University of Kansas, Center for Research on Learning.

Leake, D. W., \& Black, R. S. (2005). Implications of individualism and collectivism for the transition of youth with significant disabilities. TASH Connections, 31(11/12), 12-16. Retrieved from https://tash.org/publications-2/connections/

Lincoln, Y. S., \& Guba, E. G. (1985). Naturalistic inquiry. Beverly Hills, CA: Sage.

Loo, T. (2009). Rock, pebble, sand time management. Synergy institute. Retrieved from http://www.synergyinstituteonline.com/detail_article.php?artid=319.

McDermott, J. F., Jr., Tseng, W. S., \& Maretzki, T. W. (Eds.). (1980). People and cultures of Hawai'i - A psychocultural profile. Honolulu: University Press of Hawai'i.

McLeod, J. (2013). Increasing the rigor of case study evidence in therapy research. Pragmatic Case Studies in Psychotherapy, 9(4), 382-402. https://doi.org/10.14713/pcsp.v9i4.1832

McMullin, J. (2005). The call to life: Revitalizing a healthy Hawaiian identity. Social Science \& Medicine, 61(4), 809-820. https://doi.org/10.1016/j.socscimed.2004.08.051

Merriam, S. B. (Ed.) (2002). Qualitative research in practice. San Francisco: Jossey-Bass.

Meyer, M. A. (2003). Ho'oulu - Our time of becoming. Honolulu: 'Ai Pohaku Press.

Meyer, M. A. (2005). The role of history, intention, and function: More thoughts on Hawaiian epistemology. 'Öiwi: A Native Hawaiian Journal, 3, 32-34.

Mokuau, N., \& Matsuoka, J. (1995). Turbulence among a native people: Social work practice with Hawaiians. Social Work, 40(4), 465-472. https://doi.org/10.1093/sw/40.4.465

Mount, B. (1992). Person-centered planning: A sourcebook of values, ideas, and methods to encourage person-centered development. New York: Graphic Futures.

Ogata, V., Sheehey, P. H., \& Noonan, M. J. (2006). Rural native Hawaiian perspectives on special education. Rural Special Education Quarterly, 25(1), 7-15. https://doi.org/10.1177/875687050602500103 


\section{Macrothink}

International Journal of Learning and Development

ISSN 2164-4063 2017, Vol. 7, No. 3

Ogbu, J. U. (1990). Minority education in comparative perspective. The Journal of Negro Education, 59(1), 45-57. https://doi.org/10.2307/2295291

Rayson, A., \& Bauer, H. (1997). Chapter 8: Kamehameha II and the Coming of the Missionaries. In Hawaii: The Pacific State (pp. 35-40). US: Bess Press, Inc.

Rogers, C. A., \& Jaime, A. M. (2010). Listening to the community: Guidance from native communitymembers for emerging culturally responsive educators. Equity \& Excellence in Education, 42(2), 188-201. https://doi.org/10.1080/10665681003719657

Rynkofs, J. T. (2008). Culturally responsive talk between a second grade teacher and Native Hawaiian children during writing workshop. Educational Perspectives, 41(1-2), 44-54. Retrieved from http://files.eric.ed.gov/fulltext/EJ877777.pdf

Sargeant, J. (2012, March). Qualitative research part II: Participants, analysis, and quality assurance. Journal of Graduate Medical Education, 4(1), 1-3. https://doi.org/10.4300/JGME-D-11-00307.1

Schonleber, N. S. (2006). Culturally congruent education and the Montessori model: perspectives from Hawaiian culture-based educators (Doctoral dissertation). Available from Proquest Dissertations and Theses database. (UMI No.3216086)

Shenton, A. K., \& Hayter, S. (2004). Strategies for gaining access to organizations and informants in qualitative studies. Education for Information, 22, 223-231. https://doi.org/10.3233/EFI-2004-223-404

Silva, N. K. (1999). Ke kū'ē kūpa'a loa nei mākou: Kānaka maoli resistance to colonization (Doctoral dissertation). Available from ProQuest Dissertations and Theses database. (UMI No. 9940629)

Spall, S. (1998). Peer debriefing in qualitative research: Emerging operational models. Qualitative Inquiry, 4(2), 280-292. https://doi.org/10.1177/107780049800400208

Spradley, J. P. (1980). Participant observation. New York: Holt, Rinehart, \& Winston.

Teter, B. (2010). Hapai na leo. Curriculum, Research, and Development Group, University of Hawai'i.

Tharp, R. G., Estrada, P., Dalton, S. S., \& Yamauchi, L. (2000). Teaching transformed. Boulder, CO. Westview Press.

Trask, H. (1993). From a Native Daughter. Monroe, Maine: Common Courage Press.

Triandis, H. C. (2001). Individualism-collectivism and personality. Journal of Personality 69(6), 907-924. doi: 10.1111/1467-6494.696169

Umemoto, K. (2001). Walking in another's shoes: Epistemological challenges in participatory planning. Journal of Planning Education and Research, 21, 17-31. https://doi.org/10.1177/0739456X0102100102 


\section{Macrothink}

International Journal of Learning and Development

ISSN 2164-4063 2017, Vol. 7, No. 3

Vogler, J., Altmann, T. K., \& Zoucha, R. (2010). Native Hawaiian attitudes of culturally sensitive healthcare provider traits and behaviors. Journal of Cultural Diversity, 17(3), 90-98. Retrieved from http://web.b.ebscohost.com.eres.library.manoa.hawaii.edu/ehost/pdfviewer/ pdfviewer?vid=61\&sid=58a54f85-59ab-4086-bb47-a78fee361b1d\%40sessionmgr 102

Vygotsky, L. S. (1978). Mind in society (M. Cole, V. John-Steiner, S. Scribner, \& E. Souberman, Eds.), Cambridge, MA: Harvard Univ. Press.

Wilson, W. H., \& Kamanā, K. (2006). For the interest of the Hawaiians themselves: Reclaiming the benefits of Hawaiian-medium education. Hulili Multidisciplinary Research on Hawaiian Well-being, 3(1), 153-181.

Wlodkowski, R. J., \& Ginsbert, M. G. (1995). A framework for culturally responsive teaching. Strengthening Student Engagement, 53(1), 17-21.

Yamauchi, L. A. (2003). Making school relevant for at-risk students: The Waianae high school Hawaiian studies program. Journal of Education for Students Placed at Risk, 8(4), 379-390. https://doi.org/10.1207/S15327671ESPR0804_1

Yuen, J. W. L., Dowrick, P. W., \& Alaimaleata, E. T. (2006). Using a community response model in literacy education. In C.C. Park, R. Endo, A.L. Goodwin (Eds.), Asian and Pacific American education: Learning, socialization, and identity (pp. 121-140). A Volume in Research on the Education of Asian and Pacific-Americans. Information Age Publishing: Greenwich, CT.

\section{Copyright Disclaimer}

Copyright for this article is retained by the author(s), with first publication rights granted to the journal.

This is an open-access article distributed under the terms and conditions of the Creative Commons Attribution license (http://creativecommons.org/licenses/by/4.0/). 